\title{
Prediction of Mean Grain Size Evolution during the Forging of IN718 Turbine Disc
}

\author{
Zhang Haiyan ${ }^{1,}$, Zhang Shihong ${ }^{2}$ and Cheng Ming ${ }^{2}$ \\ ${ }^{1}$ School of Mechanical Engineering, Ningbo University of Technology, Zhejiang, Ningbo, 315016, China \\ ${ }^{2}$ Institute of Metal Research, Chinese Academy of Sciences, Shenyang, Liaoning, 110016, China
}

\begin{abstract}
The microstructure evolution during the cogging, upsetting and hot die forging in the manufacture of IN718 turbine disc has been predicted through coupling the microstructure evolution prediction system developed with a commercial finite element software. The prediction results were in good agreement with the actual ones. Furthermore, the effects of process parameters on the microstructure development during the hot die forging of IN718 turbine disc have been investigated. To design the hot die forging, a uniform function of microstructure has been proposed as the goal function.
\end{abstract}

\section{Introduction}

Superalloy IN718 is an important material used for aeroengine turbine disks because of its excellent mechanical properties in the temperature range from -253 to $650^{\circ} \mathrm{C}$ $[1,2]$. To ensure the required mechanical properties, it is crucial to obtain a uniform and fine microstructure. Generally, the sizes of turbine disks are large, and the shapes are complex. In addition, the microstructure of IN718 is sensitive to the hot deformation parameters. Therefore, the defects of coarse grain and duplex grain always appear in the forgings. Figure 1 shows the manufacturing of IN718 turbine disc [3]. At first, the ascast structure has been changed to as-forged structure during the cogging, and a big forged bar with the diameter lager than $200 \mathrm{~mm}$ has been gained. Then, though the subsequent forging processes which mainly included upsetting and closed die forging, the turbine disc forging has been obtained. At finally, the required turbine disc has been obtained by the heat treatment and the machining. As the high alloying, the thermal deformation area of alloy IN718 is narrow, and the hot deformation ability is low. In addition, the structure of alloy IN718 has transmissibility. In order to obtain the turbine disc with a uniform and fine structure, the structure in each process should been controlled in the manufacturing. Thus, it is important to understand the microstructure evolution in each process.

In the present work, the microstructure development during the cogging, upsetting and hot die forging of the turbine disc have been investigated through coupling the microstructure evolution prediction system developed with a commercial FE Software, MSC.Superform.

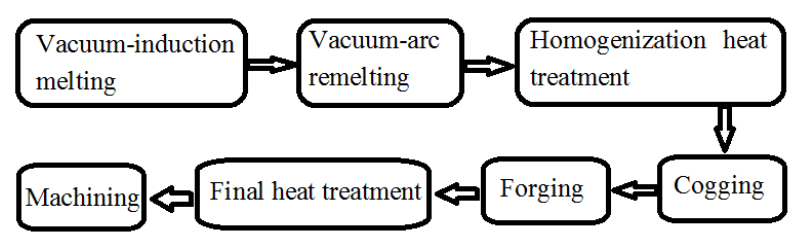

Figure 1. Manufacture of Superalloy turbine disc

\section{Microstructure simulation of the cogging}

The mechanism of microstructure evolution during the cogging is complex, which includes dynamic recrystallization (DRX), metadynamic recrystallization (MDRX), static recrystallization (SRX) and grain growth up. The microstructure evolution system during the cogging has been developed based on the molds in Ref. [4]. Figure 2 is the calculation flowchart of the microstructure evolution system during the cogging. When the recrystallized volume fraction is higher than $95 \%$, the recrystallization occurs completely, and then the grain grows up in the following deformation. For the partial recrystallization, the mean grain size is the average grain size.

Moreover, the cogging is a complex deformation process, and there are many parameters influencing the deformation. Figure 3 shows the finite element model for the cogging process. The deformation and microstructure development of section A in the middle of the billet have been analyzed. The deformation temperature of billet was $1100^{\circ} \mathrm{C}$, and the initial grain size was $2 \mathrm{~mm}$. The die temperature was $400^{\circ} \mathrm{C}$, and the reduction of the top die was $30 \mathrm{~mm}$ each pass.

\footnotetext{
a Corresponding author: zhang-hai-yan@hotmail.com
} 


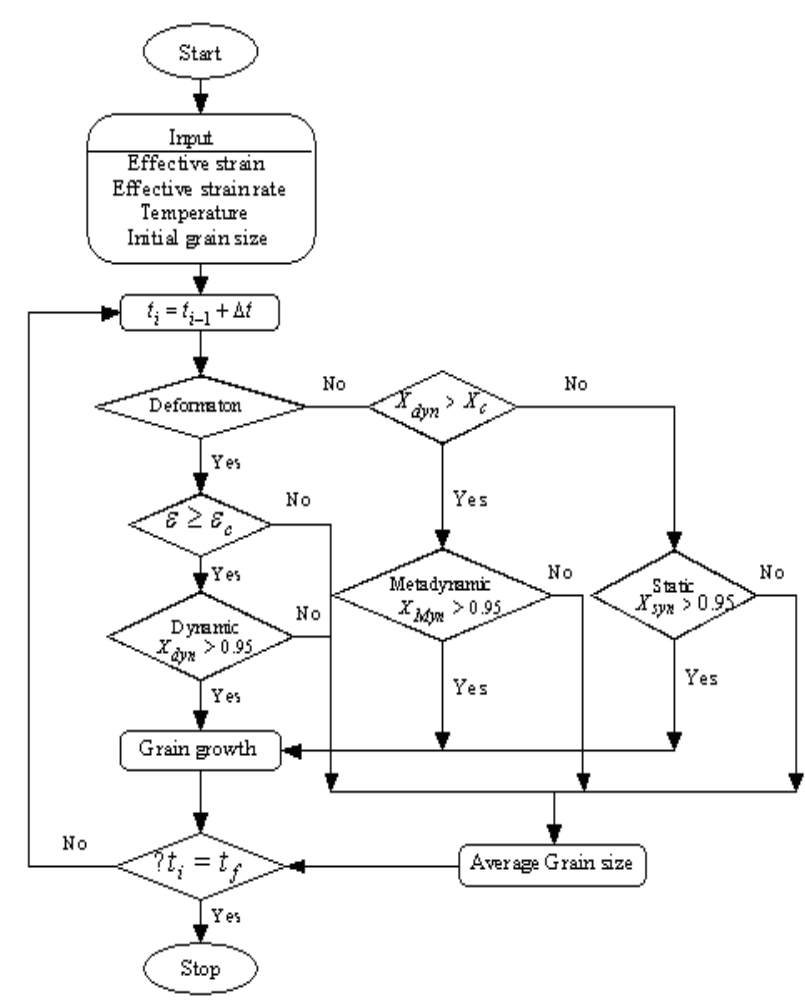

Figure 2. Calculation flow chart of the microstructure evolution system

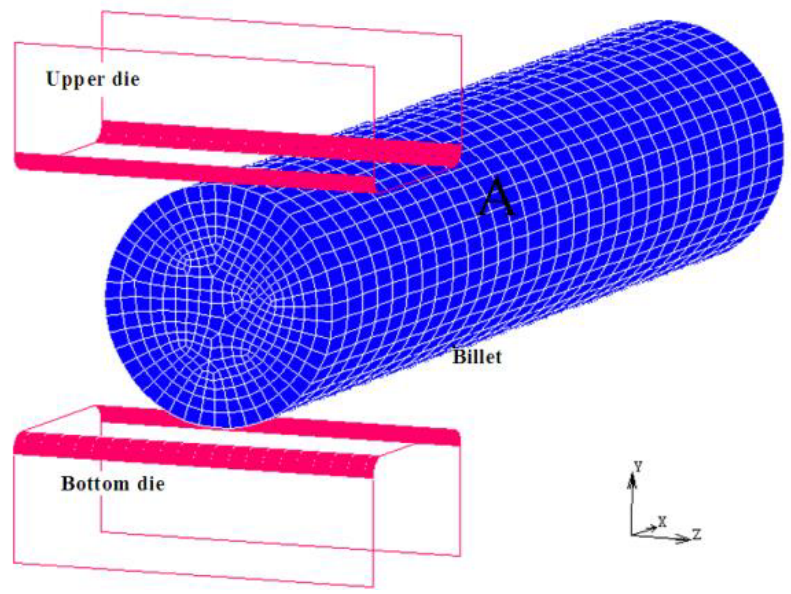

Figure 3. Finite element model for cogging process

Figure $4 \mathrm{a}-\mathrm{f}$ shows the distribution of temperature, effective strain, DRX fraction, MDRX fraction, SRX fraction and mean grain size in section $\mathrm{A}$ at the end of the fourth pass, respectively.

In Figure 4, it showed that the grain in the half radius area in the radial sections was finer due to the deformation condition in favor of the occurrence of recrystallization, and the MDRX was important for the grain refining. Furthermore, as the SRX fraction in the radial sections was higher than the DRX fraction or the MDRX fraction, the SRX was the main microstructure evolution mechanism during the cogging process of IN718 alloy.

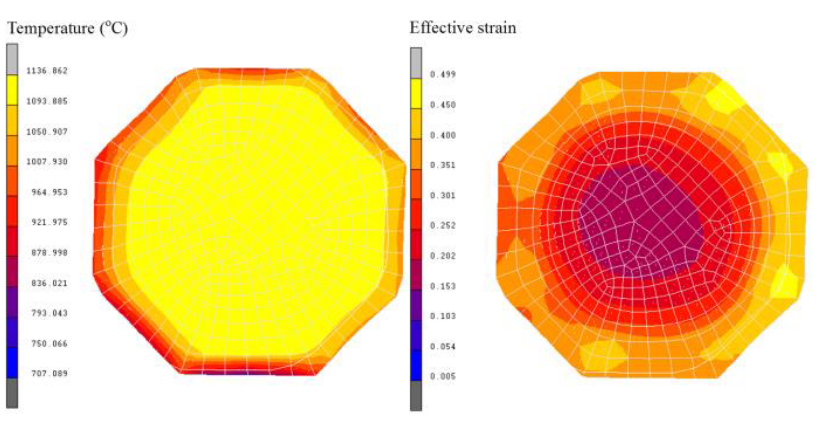

(a)

(b)
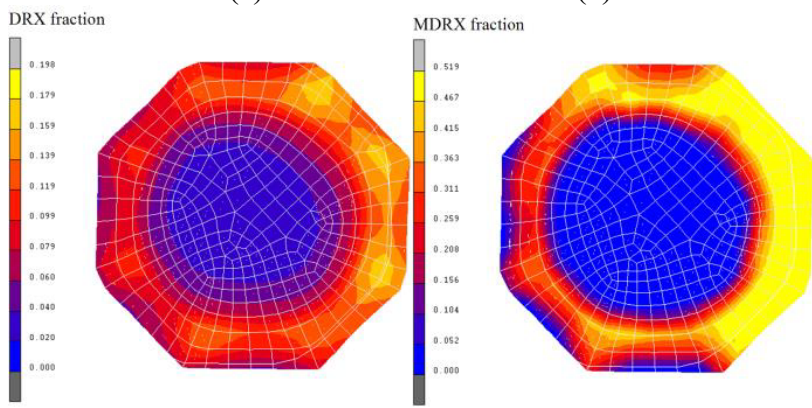

(c)

(d)

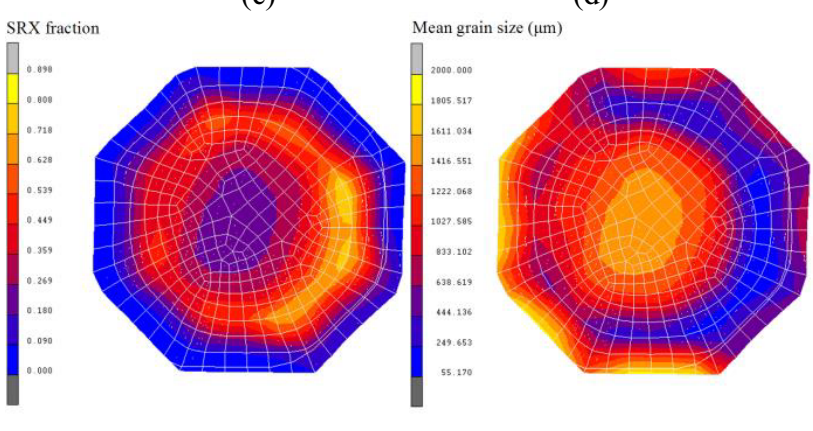

(e)

(f)

Figure 4. Distribution of temperature (a), effective strain (b), DRX fraction (c), MDRX fraction (d), SRX fraction (e) and mean grain size (f) in section $A$ at the end of fourth pass

\section{Microstructure simulation of the upsetting}

The original structure of the alloy during the forging is different with that during the cogging. So, the deformation constitutive equation and the microstructure models in terms of critical strain, DRX and grain growth for forged IN718 have been established based on the isothermal compression tests and heat treatment tests. Figure 5 is the calculation flowchart of DRX and grain growth. When the recrystallized volume fraction $X_{\text {dyn }}$ is higher than $95 \%$, DRX occurs completely, and the mean grain size is the recrystallized grain size, and then the grain grows up in the following deformation. For the partial dynamic recrystallization, the mean grain size is the average grain size davg, calculated as: $d_{\text {avg }}=(1-$ $\left.X_{\text {dyn }}\right) d_{0}+X_{\text {dyn }} d_{\text {dyn }}$, where $d_{\text {dyn }}$ and $d_{0}$ are the dynamic recrystallized grain size and initial grain size, respectively. 


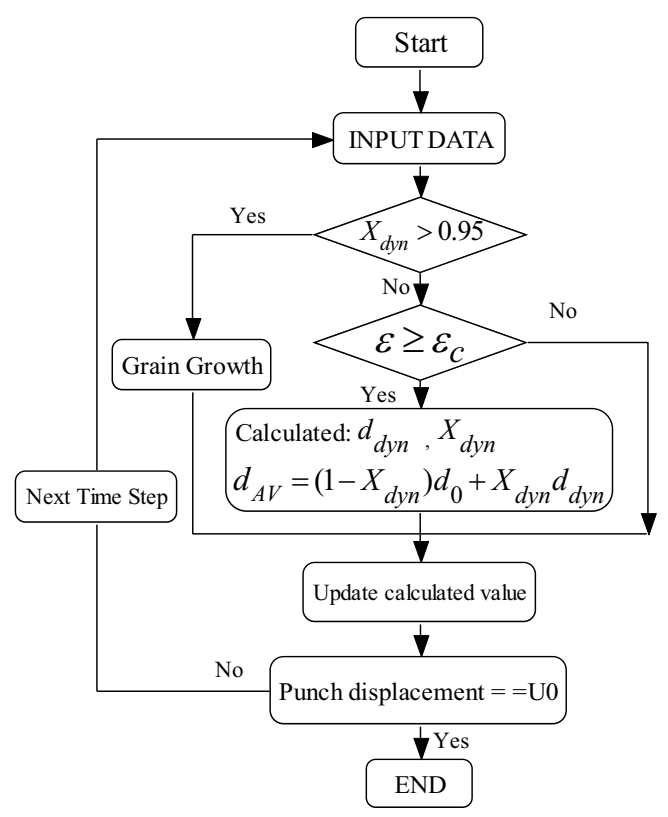

Figure 5. Calculation flowchart of DRX and grain growth

Non-isothermal upsetting experiments have been carried out to refine and validate the microstructure evolution models. Cylindrical specimens with a diameter of $53 \mathrm{~mm}$ and a height of $100 \mathrm{~mm}$ were used for the upsetting tests. Figure 6 shows the prediction of mean grain size during non-isothermal forging by FEM. The deformation temperature of workpiece was $1030^{\circ} \mathrm{C}$, and the initial grain size was $32 \mu \mathrm{m}$. The die temperature was $300^{\circ} \mathrm{C}$, and the workpiece was deformed to $70 \%$ reduction in height. It can be clearly identified three deformation zones in Figure 6: dead zone A, free deformation zone $\mathrm{B}$ and easy deformation zone $\mathrm{C}$, and. Figure 7 shows the microstructures observed in the corresponding zones of the workpiece. The predicted mean grain size is in good agreement with the observations.

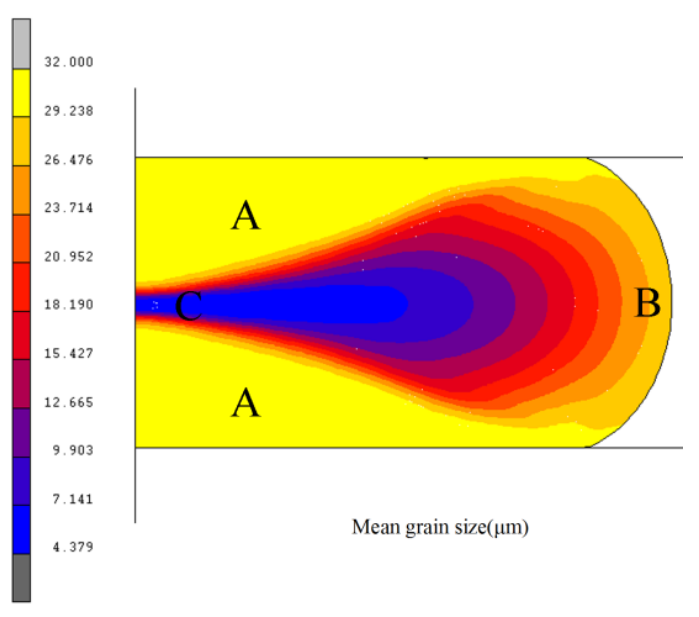

Figure 6. Prediction of mean grain size during Superalloy IN718 non-isothermal forging

Due to the effect of heat exchange and friction with dies, the top and bottom of workpiece are the dead zones during deformation. For the material located in these zones, the DRX takes place hardly (Figure 7a). The mean grain size in zone A after deformed was $45 \mu \mathrm{m}$, which was larger than the initial grain size of $32 \mu \mathrm{m}$. The reason is that the workpiece was held for 30 minutes after heated to deformation temperature to make the temperature uniform in the experiment and the original grain grew up during the holding period. As the DRX occurs completely, a uniform and fine microstructure is obtained in the easy deformation zone $C$ (Figure $7 b$ ). In the free deformation zone $\mathrm{B}$, there is a duplex grain microstructure for the uncompleted DRX (Figure 7c).

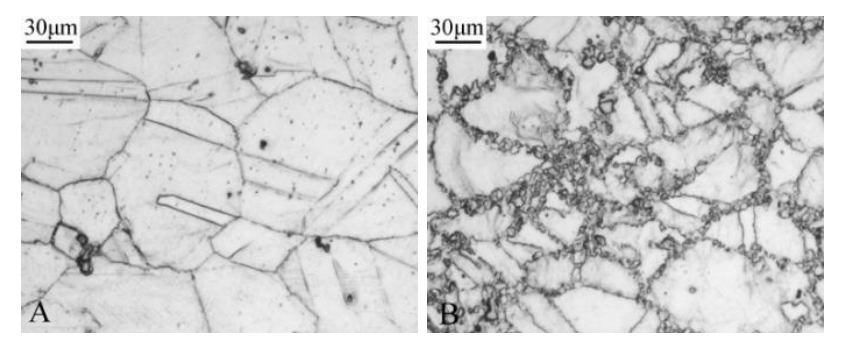

(a)

(b)

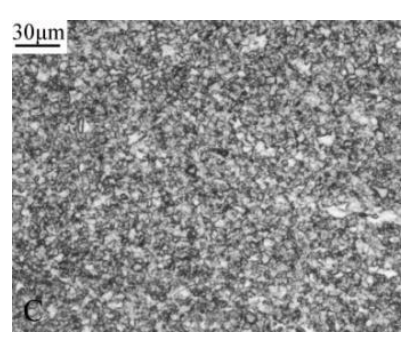

(c)

Figure 7. Microstructure in different zones of workpiece: dead zone A (a), free deformation zone B (b) and easy deformation zone $\mathrm{C}(\mathrm{c})$

Figure 8 shows the mean grain size distribution of the billet deformed under the actual upsetting condition. The size of billet is $250 \mathrm{~mm}$ in diameter and $470 \mathrm{~mm}$ in height. The initial temperature of the billet was $1030^{\circ} \mathrm{C}$, and the billet was deformed to $70 \%$ reduction in height. Due to the grain growth up during the holding period after heated to the deformation temperature, the initial grain size was $45 \mu \mathrm{m}$ in the FEM.

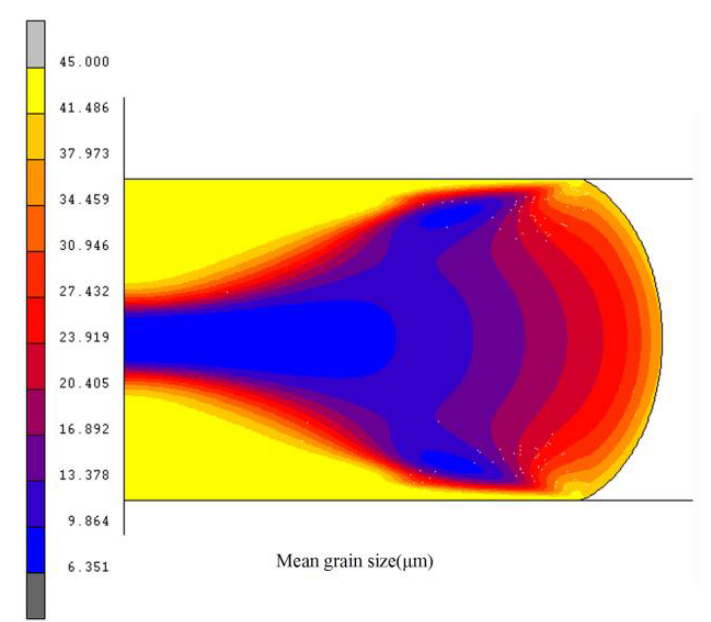

Figure 8. Mean grain size distribution of the billet deformed under the actual upsetting condition 


\section{Microstructure simulation of the hot die forging}

Figure 9 shows the mean grain size distribution in the turbine disk at the end of forging in the actual process. Five zones of coarse grain (A, B, C, D and E) can be distinctly seen in Figure 9. For the zone A, C and E, the temperature and strain are low during forging, so it is difficult for the occurrence of DRX. The material in the zone $\mathrm{B}$ and $\mathrm{D}$ flows difficultly due to the chilling of billet surface for the heat exchange with die, and it is the deformation dead zone. In the zone F, for the temperature and strain are higher, the XRD occurs abundantly and the mean grain size is smaller. Figure 10 shows the microstructures observed in the zone $\mathrm{A}$ and $\mathrm{F}$ of the turbine disk. It can be seen that the predicted mean grain size is in good agreement with the observations.

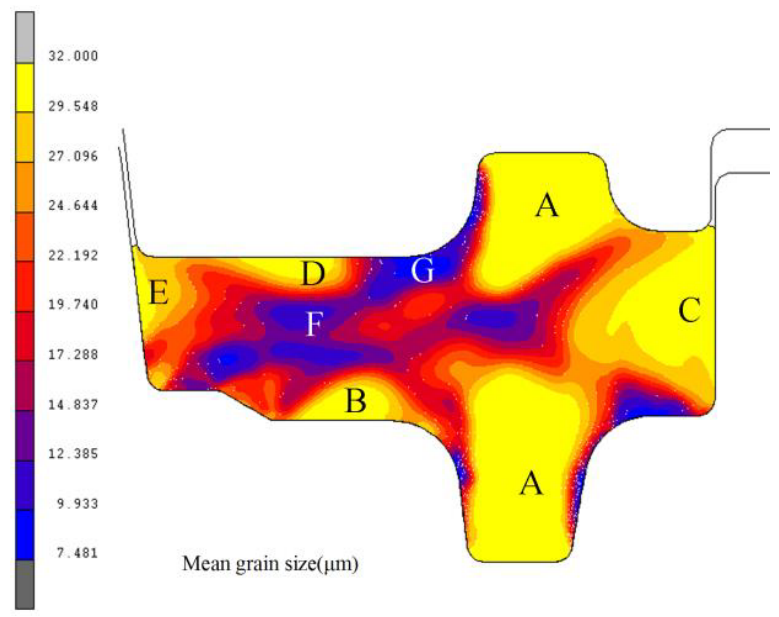

Figure 9. Mean grain size distribution in the turbine disk at the end of forging in the actual process

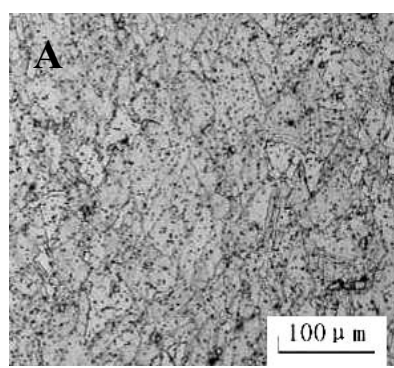

(a)

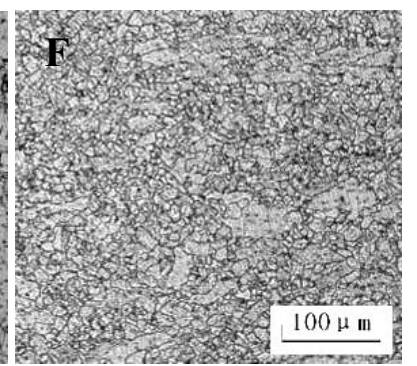

(b)
Figure 10. Microstructures observed in different zones of turbine disk: zone A (a) and zone F (b)

During the hot die forging of IN718 turbine disks, billet size, die temperature, billet temperature and deformation speed would affect the grain size. It is important to obtain a turbine disk with uniform grain size. A uniform function of microstructure $(W)$ was put forward as the objective function to design the forging of IN718 turbine disk, which is expressed as Eq. (1).

$$
W=\sum\left(d_{i}-d_{a v g}\right)^{2} / n_{1}
$$

where $d_{i}$ is the mean grain size of each element, $d_{\text {avg }}$ is the average grain size, and $n_{1}$ is the sum of elements. The smaller the value of $W$ is, the more uniform the grain size in turbine disk is. Figure 11 is effect of parameters on the uniformity of the deformation distribution function $W$. As the height and the die temperature increasing the value of $W$ increased; as the deformation speed increasing, the value of $W$ decreased. The influence of the inner diameter and die temperature on $W$ was smaller. In order to prevent the grain grow up in the high-temperature heating and heat insulation process, the optimization parameters of the turbine disk forging process are as follows: billet temperature $1000^{\circ} \mathrm{C}$, die temperature $900^{\circ} \mathrm{C}$.

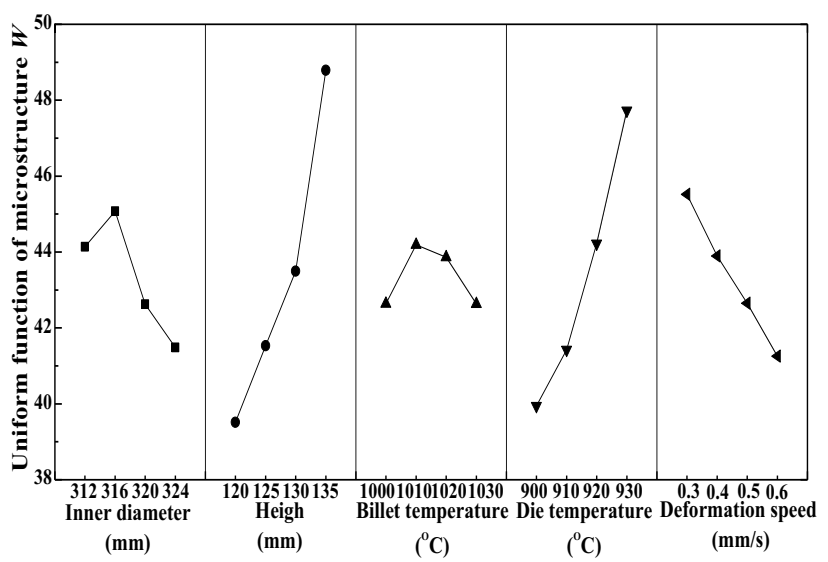

Figure 11. Effect of process parameters on the uniform function of microstructure W

Figure 12 shows the mean grain size distribution in the turbine disk at the end of forging under the optimum hot die forging condition. Compare to the actual forging process (Figure 9), the mean grain size distribution in the zone $\mathrm{F}$ is more uniform under the optimization parameters (Figure 12). The mean grain size in the zone $\mathrm{A}$ and $\mathrm{C}$ are finer than that in the actual forging process. But there is no improvement for the coarse grain in the zone $\mathrm{B}, \mathrm{D}$ and $\mathrm{E}$ (Figure 12). The value of $W$ under the actual forging process and the optimum forging process is 50.49 and 32.29, respectively. Therefore, the optimum process is helpful to obtain the turbine disk with a uniform grain size.

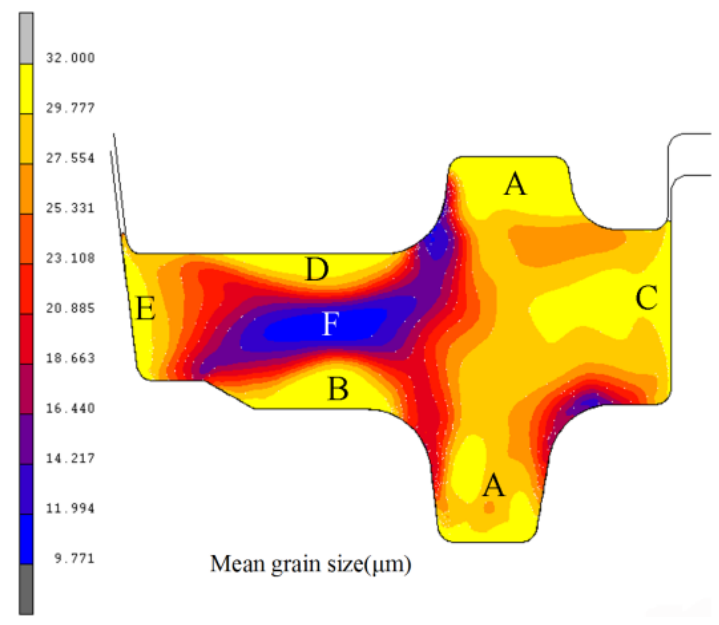

Figure 12. Mean grain size distribution in the turbine disk at the end of forging under the optimum forging condition 


\section{Conclusions}

(1) During the cogging of IN718, the grain in the half radius area in the radial sections was finer as the deformation condition in favor of the occurrence of recrystallization. MDRX was important for the grain refining, and SRX was the main microstructure evolution mechanism during the cogging process.

(2) During the upsetting, there were three deformation zones in the billet. In the dead zone, the DRX took place hardly. In the free deformation zone, there was a duplex grain microstructure for the uncompleted DRX. In the easy deformation zone, a uniform and fine microstructure was obtained as the DRX occurred completely.

(3) The effect of billet size, die temperature and deformation speed on the microstructure evolution during the hot die forging of IN718 turbine disk were investigated by FEM. A uniform function of microstructure was put forward as the objective function to optimize the hot die forging process.

\section{Acknowledgments}

This work has been supported by the National Natural Science Foundation of China with the Grant Number: 51505240, the Natural Science Foundation of Zhejiang with the Grant Number: LY15E050008, and the Natural Science Foundation of Ningbo with the Grant Number: 2015A610068. In addition, the author gratefully acknowledges the support of K.C.Wong Education, Hong Kong.

\section{References}

1. R.E. Schafrik, D.D. Ward, J.R. Groh, Superalloys 718, 625, 706 and Various Derivatives, 1 (TMS, Warrendale, 2001 )

2. D.F. Paulonis, J.J. Schirra, Superalloys 718, 625, 706 and Various Derivatives, 13 (TMS, Warrendale, 2001)

3. S. Tin, P.D. Lee, A. Kermanpur, Metal. Mater. Trans. A, 36, 2493 (2005)

4. J.T. Yeom, C.S. Lee, J.H. Kim, N.K. Park, Mater. Sci. Engng. A, 449-451, 722 (2007) 